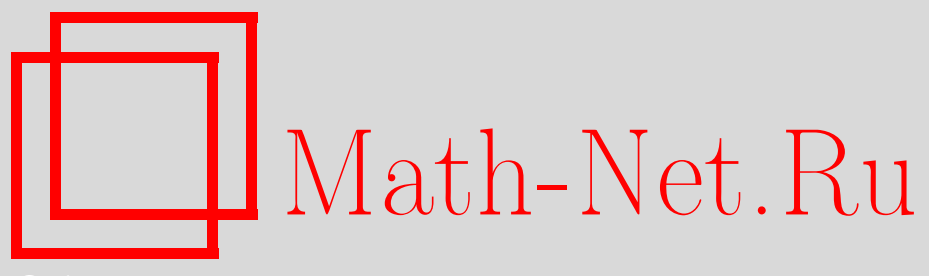

В. А. Александров, А. А. Борисенко, Ю. Ф. Борисов, Ю. Д. Бураго, В. В. Вершинин, Е. П. Волокитин, Л. И. Кононенко, С. С. Кутателадзе, Ю. Г. Решетняк, Е. Д. Родионов, А. С. Романов, С. А. Тресков, В. А. Шарафутдинов, Виктор Андреевич Топоногов (некролог), УМH, 2006, том 61, выпуск 2, 153-156

DOI: https://doi.org/10.4213/rm1740

Использование Общероссийского математического портала Math-Net.Ru подразумевает, что вы прочитали и согласны с пользовательским соглашением http://www.mathnet.ru/rus/agreement

Параметры загрузки:

IP : 54.198 .187 .58

26 апреля 2023 г., 15:02:48

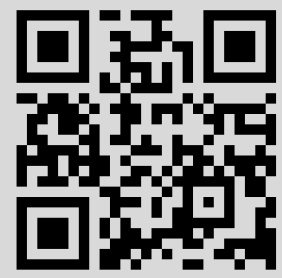




\section{Виктор Андреевич Топоногов}

Виктор Андреевич Топоногов, выдающийся геометр, ушел из жизни 21 ноября 2004 года после тяжелой и долгой болезни.

Он родился 6 марта 1930 года в Томске, старом сибирском университетском городе. Там же прошло детство Виктора Андреевича. Его отец был репрессирован в 1937 году. После окончания в 1948 году средней школы В. А. Топоногов поступил на механико-математический факультет Томского университета, который окончил в 1953 году, получив диплом с отличием, но, как сын "врага народа", не мог надеяться поступить в аспирантуру. В марте 1953 года умер Сталин. Ситуация в стране изменилась, и В.А. Топоногов был зачислен в аспирантуру Томского университета. Его математические интересы сформировались под влиянием Абрама Ильича Фета, научного руководителя по аспирантуре, и работ Алек-

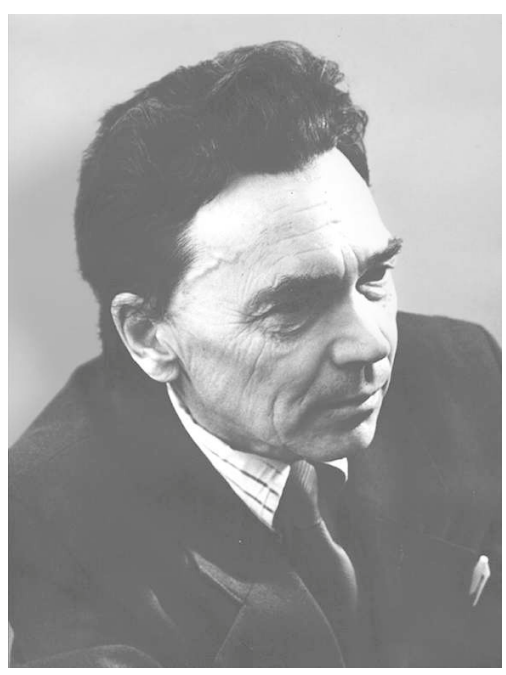
сандра Даниловича Александрова.

В 1956 году Виктор Андреевич переехал в Новосибирск, где в апреле 1957 года стал научным сотрудником новосибирского Института радиофизики и электроники, возглавляемого тогда Юрием Борисовичем Румером.

В декабре 1958 года В.А. Топоногов защитил в Московском университете кандидатскую диссертацию, в которой теорема А. Д. Александрова о сравнении углов была перенесена на многомерные римановы многообразия. В апреле 1961 г. В. А. Топоногов перешел на работу в создававшийся в то время Институт математики Сибирского отделения АН СССР. С Институтом математики связана вся последующая научная деятельность Виктора Андреевича. В 1969 году он защитил докторскую диссертацию на тему "Экстремальные теоремы для римановых пространств кривизны, ограниченной сверху". В начале 1980-х годов В. А. Топоногов работал заместителем директора института, с 1982 по 2000 год возглавлял одну из лабораторий, а затем до конца жизни работал главным научным сотрудником.

Первые тридцать лет своей научной деятельности Виктор Андреевич посвятил одному из важнейших разделов современной геометрии - римановой геометрии "в целом". Он наряду с Э. Картаном, М. Морсом, Г. Раухом и В. Клингенбергом был одним из тех, кто превратил риманову геометрию из сугубо локальной теории в современную глобальную риманову геометрию. Именно в этой области им получены классические результаты, которые легли в фундамент современной геометрии. Это, в первую очередь, знаменитая теорема Топоногова о сравнении углов треугольников, которая утверждает, что углы любого треугольника из кратчайших в полном римановом многообразии кривизны не меньше $k$ не меньше углов треугольника со сторонами той же длины на односвязной поверхности постоянной кривизны $k$. Именно на этом 
глубоком результате основывается первое доказательство важной теоремы о сфере. Этот же результат лег в основу последующих многочисленных исследований связей между кривизной и топологическим строением римановых многообразий, а также поведением геодезических. Следующий фундаментальный результат В. А. Топоногова - теорема о расщеплении, утверждающая, что риманово многообразие неотрицательной кривизны, содержащее прямую - полную геодезическую, любой участок которой является кратчайшей, разлагается в прямое метрическое произведение. Далее, Виктор Андреевич получил тонкие экстремальные теоремы, характеризующие римановы многообразия, имеющие максимально возможные при данной нижней грани кривизны диаметр или замкнутую геодезическую. Эти и другие теоремы В. А. Топоногова включены в современные учебники по римановой геометрии и в монографии различных авторов, а его методы оказали существенное влияние на развитие современной римановой геометрии. Достаточно сказать, что в современную геометрию прочно вошел термин САТ-пространство, поставивший рядом имена Картана, Александрова и Топоногова.

В последнее десятилетие своей жизни В.А. Топоногов вел исследования в области дифференциальной геометрии двумерных поверхностей в трехмерном евклидовом пространстве. Им были получены существенные продвижения в вопросах, связанных с теоремой Н.В. Ефимова о невозможности изометрического погружения в трехмерное евклидово пространство полной римановой метрики, отделенной от нуля отрицательной кривизны и с гипотезой Милнора об отсутствии погружений, у которых сумма модулей главных кривизн равномерно отделена от нуля.

Со времени совместной работы с Ю.Б. Румером у Виктора Андреевича возник интерес к связям математики с естественными науками. В 1980-1990-е годы им было выполнено несколько работ по математическим методам в химии.

Более 40 лет он вел активную педагогическую деятельность в Новосибирском государственном университете и педагогическом институте. Из множества курсов, им прочитанных, особенно замечательны курсы дифференциальной и римановой геометрии, математического анализа. Работая в различных областях математики, много преподавая, Виктор Андреевич обладал широкой математической эрудицией и щедро делился ею с молодежью. Более десяти учеников В. А. Топоногова защитили кандидатские, и многие из них - докторские диссертации.

Хотя Виктор Андреевич получил классические результаты, вызвавшие большой международный резонанс, он не получал ни престижных премий, ни академических регалий, ни важных государственных наград. Зато всю жизнь он оставался самим собой, был человеком открытым и свободным в своем творчестве и мировоззрении.

В. А. Топоногов был одним из старожилов новосибирского Академгородка. Конец пятидесятых - шестидесятые годы были временем большого научного подъема и энтузиазма в стране, в частности, был создан Академгородок. Именно эти годы были пиком научного творчества Виктора Андреевича.

Виктор Андреевич был разносторонним человеком. Прекрасный шахматист, он еще в студенческие годы вел шахматный кружок в Доме пионеров. Много ходил по сибирской тайге, сплавлялся по сибирским рекам, был заядлым лодочником. У него всегда было много друзей, которые будут помнить его заразительный жизнерадостный смех.

Виктор Андреевич прожил достойную жизнь. Его друзья и коллеги чувствуют глубокую утрату и через всю жизнь пронесут память об этом замечательном человеке и глубоком ученом.

В.А. Александров, А.А. Борисенко, Ю.Ф. Борисов, Ю. Д. Бураго, В.В. Вершинин, Е. П. Волокитин, Л. И. Кононенко, С. С. Кутателадзе, Ю.Г. Решетняк, Е.Д. Родионов, А.С. Романов, С.А. Тресков, В.А. Шарафутдинов 


\section{Список печатных работ В. А. Топоногова}

[1] “Свойство выпуклости римановых пространств положительной кривизны”, Докл. AH CCCP, 115:4 (1957), 674-676.

[2] "Римановы пространства кривизны, ограниченной снизу положительном числом", Докл. АН СССР, 120:4 (1958), 719-722.

[3] "Оценка длины замкнутой геодезической на выпуклой поверхности", Докл. АН ССCP, 124:2 (1959), 282-284.

[4] "Римановы пространства, содержащие прямые линии", Докл. АН СССР, 127:5 (1959), 977-979.

[5] "Римановы пространства кривизны, ограниченной снизу”, УМН, 14:1 (1959), 87130.

[6] "Зависимость между кривизной и топологическим строением римановых пространств четной размерности", Докл. АН СССР, 133:5 (1960), 1031-1033.

[7] "Оценка длины выпуклой кривой на двумерной поверхности”, Сиб. матем. журн., 4:5 (1963), 1189-1193.

[8] "Метрическое строение римановых пространств неотрицательной кривизны, содержащих прямые линии", Сиб. матем. журн., 5:6 (1964), 1358-1369.

[9] "Оценка длины замкнутой геодезической в компактном римановом пространстве положительной кривизны”, Докл. АН СССР, 154:5 (1964), 1047-1049.

[10] "Одна теорема о римановых пространствах, содержащих прямые линии", Тезисы докладов Международного конгресса математиков (М., 1966), М., 1966, 170-171.

[11] "Некоторые экстремальные теоремы римановой геометрии", Сиб. матем. журн., 8:5 (1967), 1079-1103.

[12] "Одна экстремальная теорема римановой геометрии", 2-й Всесоюзный симпозиум по геометрии в целом, Петрозаводск, 1967, 67.

[13] "Изопериметрическое неравенство для поверхностей, гауссова кривизна которых ограничена сверху", Сиб. матем. журн., 10:1 (1969), 144-157.

[14] “Экстремальные теоремы для римановых пространств кривизны, ограниченной сверху", Докл. АН СССР, 184:2 (1969), 300-302.

[15] "Теоремы о кратчайших в некомпактных римановых пространствах положительной кривизны", Докл. АН СССР, 191:3 (1970), 537-539.

[16] "Некомпактные пространства отрицательной кривизны", Дополнение к кн.: Д. Громол, В. Клингенберг, В. Мейер, Риманова геометрия в иелом, Мир, М., 1971, 298-337.

[17] "Одно характеристическое свойство четырехмерного симметрического пространства ранга 1", Сиб. матем. журн., 13:4 (1972), 884-902.

[18] "О трехмерных римановых пространствах ограниченной сверху кривизны", Матем. заметки, 13:6 (1973), 881-887 (совм. с Ю. Д. Бураго).

[19] “Экстремальные теоремы для римановых пространств с кривизной, ограниченной сверху. I", Сиб. матем. журн., 15:6 (1974), 1348-1371.

[20] "Римановы пространства с диаметром, равным $\pi$ ", Сиб. матем. журн., 16:1 (1975), 124-131.

[21] "Погруженных многообразий геометрия", Матем. энииклопедия, т. 4, Советская энциклопедия, М., 1984, 359-363 (совм. с С. З. Шефелем).

[22] "Риманова геометрия", Матем. энииклопедия, т. 4, Советская энциклопедия, М., 1984, 1003-1010.

[23] "Риманова геометрия в целом", Матем. энииклопедия, т. 4, Советская энциклопедия, М., 1984, 1010-1013 (совм. с Ю. Д. Бураго). 
[24] "Простая модель разветвленно-цепной реакции, описывающая колебательный режим”, Писъма в кинетику и горение, 25:3-4 (1984), 301-304 (совм. с В. И. Бабушок и В. М. Гольдштейном).

[25] “Экстремальный случай теоремы сравнения углов треугольника", Сиб. матем. журн., 26:1 (1985), 206-209 (совм. с А. И. Веденяпиным и Е. Д. Мазаевым).

[26] "Открытые многообразия неотрицательной кривизны Риччи с быстро растущим объемом", Сиб. матем. журн., 26:4 (1985), 191-194 (совм. с В. Б. Мареничем).

[27] “Теорема сравнения углов треугольника для одного класса римановых многообразий”, Тр. Ин-та математики СО РАН СССР, 9, Новосибирск, 1987, 16-25 (совм. с С. А. Акбаровым).

[28] "Геометрическая характеризация комплексного проективного пространства", Геометрия и топология однородных пространств, Алтайск. гос. ун-т, Барнаул, 1988, 98-104 (совм. с В. Ю. Ровенским).

[29] Открытые многообразия неотрицательной кривизны Итоги науки и техники. Проблемы геометрии, 21, ВИНИТИ, М., 1989, 67-91 (совм. с В. Б. Мареничем).

[30] "Одно достаточное условие отсутствия цикла в двумерной системе, квадратичной по одной переменной", Сиб. матем. журн., 34:2 (1993), 170-172.

[31] “Поверхности обобщенной постоянной ширины”, Сиб. матем. журн., 34:3 (1993), 179-189.

[32] "Теорема единственности для поверхности, у которой главные кривизны связаны соотношением $\left(1-k_{1} d\right)\left(1-k_{2} d\right)=-1$ ", Сиб. матем. журн., 34:4 (1993), 197-199.

[33] “Теорема о цилиндре для выпуклых гиперповерхностей”, Сиб. матем. журн., 35:4 (1994), 915-918.

[34] "Об условиях существования омбилических точек на выпуклой поверхности", Сиб. матем. журн., 36:4 (1995), 903-910.

[35] "Об условиях существования периодических решений системы обыкновенных дифференциальных уравнений с заданными интегральными характеристиками", Сиб. матем. журн., 36:5 (1995), 1157-1166.

[36] Тензорная алгебра и тензорный анализ, Курс лекций для студентов физ. ф-та НГУ, Новосиб. гос. ун-т, Новосибирск, 1995.

[37] Практические занятия по основаниям геометрии, Метод. указ., Новосиб. гос. пед. ун-т, Новосибирск, 1995 (совм. с Н.А.Буровой).

[38] "Теорема единственности для выпуклых поверхностей без омбилических точек, у которых главные кривизны связаны некоторым соотношением", Сиб. матем. журн., 37:5 (1996), 1176-1180.

[39] "Теорема Чигера-Громолла для одного класса открытых многообразий с ограниченной снизу кривизной в интегральном смысле", Сиб. матем. журн., 38:1 (1997), 208-216.

[40] "Great sphere foliations and manifolds with curvature bounded from above", Appendix A in book: V. Rovenskii, Foliations on Riemannian manifolds and submanifolds, Birkhäuser, Boston, MA, 1998, 218-234 (with V. Rovenskii). 